\title{
Thermodynamic and Energy Efficiency Analysis of a Domestic Refrigerator Using $\mathrm{Al}_{2} \mathrm{O}_{3}$ Nano-Refrigerant
}

\author{
Farhood Sarrafzadeh Javadi ${ }^{1,2}$ and Rahman Saidur ${ }^{3,4, *}$ \\ 1 Department of Mechanical Engineering, Faculty of Engineering, University of Malaya, \\ Kuala Lumpur 50603, Malaysia; fjavadi2001@gmail.com or farhood.javadi@adriansvc.com \\ 2 Center of Technology and Innovation, Adrian Integrated Services Sdn Bhd, Kuala Lumpur 53300, Malaysia \\ 3 Research Center for Nano-Materials and Energy Technology (RCNMET), School of Engineering \\ and Technology, Sunway University, Petaling Jaya 47500, Malaysia \\ 4 Department of Mechanical and Manufacturing Engineering, Faculty of Engineering, \\ Universiti Putra Malaysia, Serdang 43400, Malaysia \\ * Correspondence: saidur@sunway.edu.my
}

check for updates

Citation: Sarrafzadeh Javadi, F.; Saidur, R. Thermodynamic and Energy Efficiency Analysis of a Domestic Refrigerator Using $\mathrm{Al}_{2} \mathrm{O}_{3}$

Nano-Refrigerant. Sustainability 2021, 13, 5659. https://doi.org/ $10.3390 /$ su13105659

Academic Editors:

Mehdi Seyedmahmoudian,

Alex Stojcevski, Ben Horan and Saad Mekhilef

Received: 13 April 2021

Accepted: 5 May 2021

Published: 18 May 2021

Publisher's Note: MDPI stays neutral with regard to jurisdictional claims in published maps and institutional affiliations.

Copyright: (c) 2021 by the authors. Licensee MDPI, Basel, Switzerland. This article is an open access article distributed under the terms and conditions of the Creative Commons Attribution (CC BY) license (https:/ / creativecommons.org/licenses/by/ $4.0 /)$.

\begin{abstract}
Refrigeration systems have experienced massive technological changes in the past 50 years. Nanotechnology can lead to a promising technological leap in the refrigeration industry. Nanorefrigerant still remains unknown because of the complexity of the phase change process of the mixture including refrigerant, lubricant, and nanoparticle. In this study, the stability of $\mathrm{Al}_{2} \mathrm{O}_{3}$ nanofluid and the performance of a nano-refrigerant-based domestic refrigerator have been experimentally investigated, with the focus on the thermodynamic and energy approaches. It was found that by increasing the nanoparticle concentration, the stability of nano-lubricant was decreased and evaporator temperature gradient was increased. The average of the temperature gradient increment in the evaporator was $20.2 \%$ in case of using $0.1 \%-\mathrm{Al}_{2} \mathrm{O}_{3}$. The results showed that the energy consumption of the refrigerator reduced around $2.69 \%$ when $0.1 \%-\mathrm{Al}_{2} \mathrm{O}_{3}$ nanoparticle was added to the system.
\end{abstract}

Keywords: nano-refrigerant; nanofluid; refrigerator; energy efficiency; thermodynamic analysis; aluminum oxide

\section{Introduction}

In the past 50 years, refrigeration systems have experienced massive technological changes. Many of the recent changes in refrigeration systems are due to the rapid changes in technology and environmental challenges. Beside the harmful effect of refrigerant on the environment, scientists have warned that the continuous release of refrigerants into the atmosphere will destroy the Earth's ozone layer. Ozone layer depletion might lead to global warming followed by natural disasters. HFC-134a (R134a) is the most common refrigerant used in domestic refrigerators due to zero ozone depletion potential (ODP), low global warming potential (GWP), being non-flammable, and favorable thermodynamic properties [1,2].

Application of nanomaterials in various fields of engineering has become an interesting topic and remained challenging in some aspects during the last two decades [3-7]. Since 1995, when the term nanofluid was introduced by Choi [8] to describe a new class of heat transfer fluids, many studies have been conducted in this field to discover advantages and disadvantages in order to overcome the application barriers [9-11]. The main objective has been to create a new type of coolant with higher heat transfer capability, which has been used in variety of products such as computers, power electronics, car engines, heat exchangers, and high-powered lasers. Enhancement in thermal properties such as thermal conductivity due to the presence of nanoparticles has attracted great interest of researchers, but instability of nano-size solid particles in the basefluid, especially at high concentrations, 
still remains a challenge in its application [12-15]. Many studies have been conducted on the fundamental properties, application, and characterization of different types of nanoparticles dispersed in different base fluids [16-19]. However, application of nanoparticle in a low temperature base fluid such as refrigerant remains unknown because of the difficulties during measuring the fundamental properties of the mixture and liquid-to-vapor phase change of the fluid. Therefore, the function of nano-refrigerant in a phase-change process including migration of nanoparticle during boiling, sedimentation, and thermophysical characteristics of different phases is very controversial.

Comparatively, few investigations have considered certain effects of nano-refrigerant on the refrigeration system, and most of them have evaluated the fundamental properties of nano-refrigerants $[20,21]$ or impacts of using nano-refrigerant on the heat transfer characteristics in a pipe [22-24]. In addition, it is essential to consider the applicability of nano-refrigerants in a real refrigeration system.

There are a limited number of investigations on nano-refrigerants available in the literature. Peng et al. [22] have investigated the heat transfer characteristics of the flow boiling of a refrigerant-based nanofluid inside a horizontal smooth tube. They have found that the heat transfer coefficient of the nanofluid is larger than that of the pure refrigerant. The nucleate pool boiling heat transfer enhancement of refrigerant-based nanofluid with low concentration of additives was reported by Peng et al. [23]. The experiment by Henderson et al. [24] on the flow-boiling of R-134a/polyolester mixture showed that the heat transfer coefficient increased more than $100 \%$ over the baseline by adding $\mathrm{CuO}$ nanoparticle into the mixture. In a fundamental aspect, several experimental articles investigated the characterization of refrigerant-based nanofluid $[20,21,25,26]$. There are only two articles available reporting the effect of refrigerant-based nanofluid in a refrigeration system. According to the work done by Bi et al. [25], R-134a/mineral oil with $\mathrm{TiO}_{2}$ nanoparticles worked normally in the refrigerator and the performance of refrigerator was better than that of R-134a and POE oil. The improved refrigerator performance with $\mathrm{TiO}_{2}-\mathrm{R} 600$ a nano-refrigerant compared to pure R600a was achieved experimentally by $\mathrm{Bi}$ et al. [26] as well.

Influence of $\mathrm{CuO}$ nanoparticles on the boiling performance of $\mathrm{R} 134 \mathrm{a} /$ polyolester lubricant oil mixture was experimentally investigated by Kedzierski et al. [27]. The experiment was done on a roughened, horizontal, and flat surface. They found $50 \%$ to $275 \%$ heat transfer improvement for R134a/ polyolester by adding $0.5 \%$ mass fraction of $\mathrm{CuO}$ nanoparticle. The average boiling heat transfer enhancement was $19 \%$ and $12 \%$ in case of using $1 \%$ and $2 \%$ nanoparticle loading concentration, respectively. They also concluded that the thermal conductivity of the lubricant was increased around $20 \%$. The result of the same investigation done by Kedzierski [28], showed $400 \%$ heat transfer improvement by adding $0.5 \%$ mass fraction of $\mathrm{Al}_{2} \mathrm{O}_{3}$ nanoparticles into the $\mathrm{R} 134 \mathrm{a}$ / polyolester lubricant oil.

The feasibility of synthesis of refrigerant-based nanofluids, as well as characterizing their thermal behavior, must be taken into consideration.

In recent years, some studies have been reported on phase-change heat transfer of nanofluid. Most of them focused on pool boiling heat transfer. Two-phase flow heat transfer investigation was studied by Bartelt et al. [29]. The effect of $\mathrm{CuO}$ nanoparticle on the flow boiling of R134a/POE mixtures in a horizontal tube was examined. At least, $42 \%$ and $50 \%$ heat transfer enhancements were concluded as the effect of using $1 \%$ and $2 \%$ mass fraction of nanoparticles, respectively. No effect on the heat transfer coefficient was observed in case of using $0.5 \%$ mass fraction of $\mathrm{CuO}$ nanoparticle.

Household refrigerator freezer market is one of the major segments of the refrigeration industry. The widespread use of household refrigerator freezers provides an opportunity for sustainable energy saving, and the 100 million new units sold annually around the world represent a considerable potential of energy consumption in this field. Consequently, it can lead to huge amounts of energy saving by considering the energy consumption reduction methods. 
This study investigates the performance of a domestic refrigerator using nano-refrigerant by focusing on the thermodynamic and energy approach. To analyze the thermodynamic and energy efficiency of the domestic refrigerator, experimental study was conducted, and the effect of different mass fractions of nanoparticles were investigated. This study can be a viable means of elucidating the effect of nanoparticles on the performance of the refrigeration systems.

\section{Materials and Methods}

The domestic refrigerator used in the experiment was a SR 30NMB type manufactured by Samsung Company Limited, which was a double-door, freezer and refrigerator, evaporator fin type, and natural convection condenser type. The picture of the refrigerator which was used as a test-rig and the schematic diagram of the experimental set-up and the charging mechanism, are shown in Figures 1 and 2, respectively. This refrigerator was designed to work with $\mathrm{R}-134$ a refrigerant and the technical specifications are shown in Table 1.

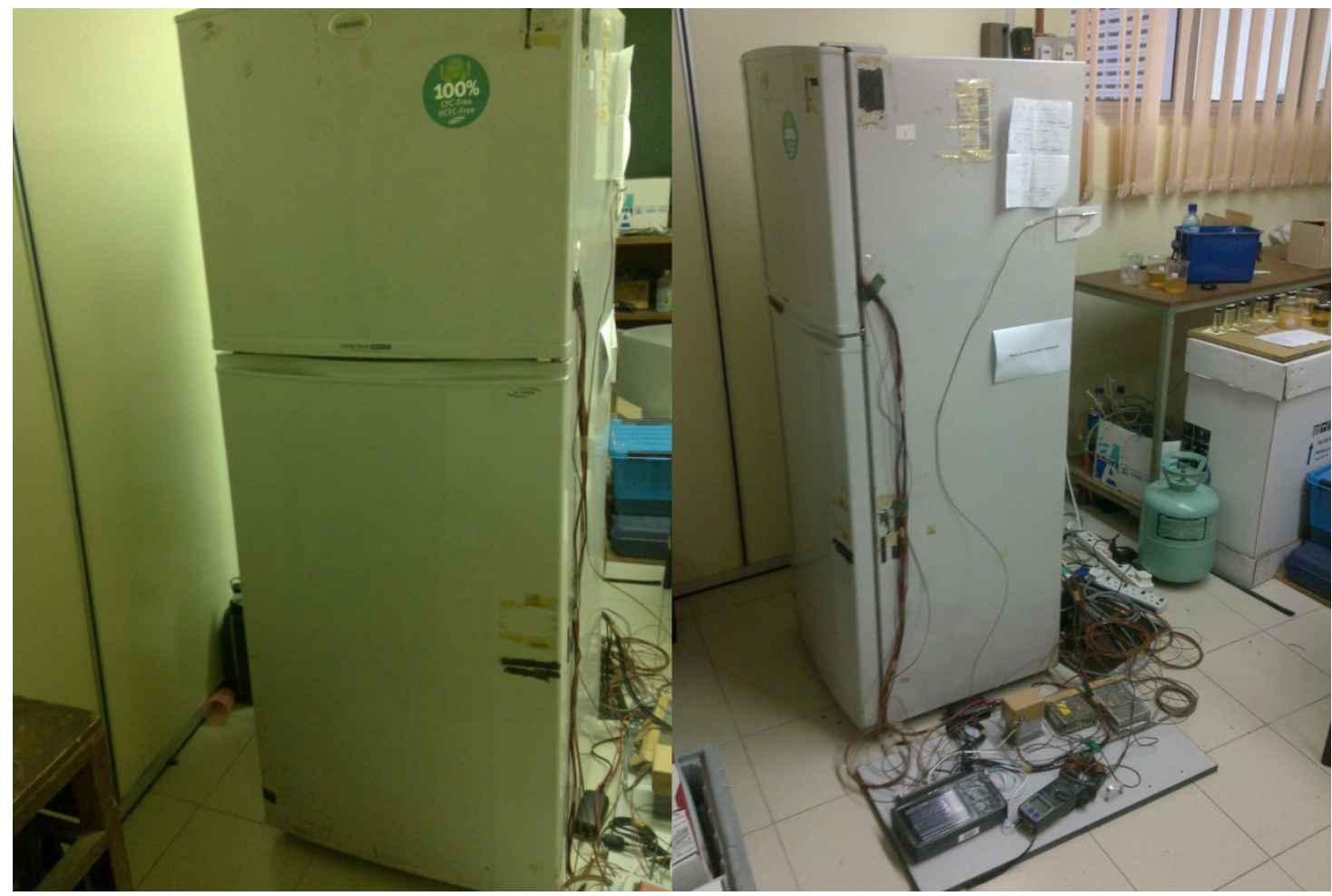

Figure 1. Domestic refrigerator test-rig.

Table 1. Technical specifications of refrigerator test unit.

\begin{tabular}{|c|c|c|}
\hline \multicolumn{2}{|c|}{ Item } & Specification \\
\hline \multicolumn{2}{|c|}{ Model name } & SR $30 \mathrm{NMB}$ \\
\hline \multicolumn{2}{|c|}{ Type } & 2-Door Freezer/refrigerator \\
\hline \multicolumn{2}{|c|}{ Power source } & $230 \sim 240 \mathrm{~V} / 50 \mathrm{~Hz}$ \\
\hline \multirow{3}{*}{$\begin{array}{l}\text { Net Capacity } \\
\text { Lit (cu.ft.) }\end{array}$} & Freezer & $68(2.4)$ \\
\hline & Refrigerator & $186(6.6)$ \\
\hline & Total & $254(9.0)$ \\
\hline \multicolumn{2}{|c|}{ Refrigerant } & R 134a (140 g) \\
\hline \multicolumn{2}{|c|}{ Compressor model } & SD162CL1U/T3 \\
\hline
\end{tabular}




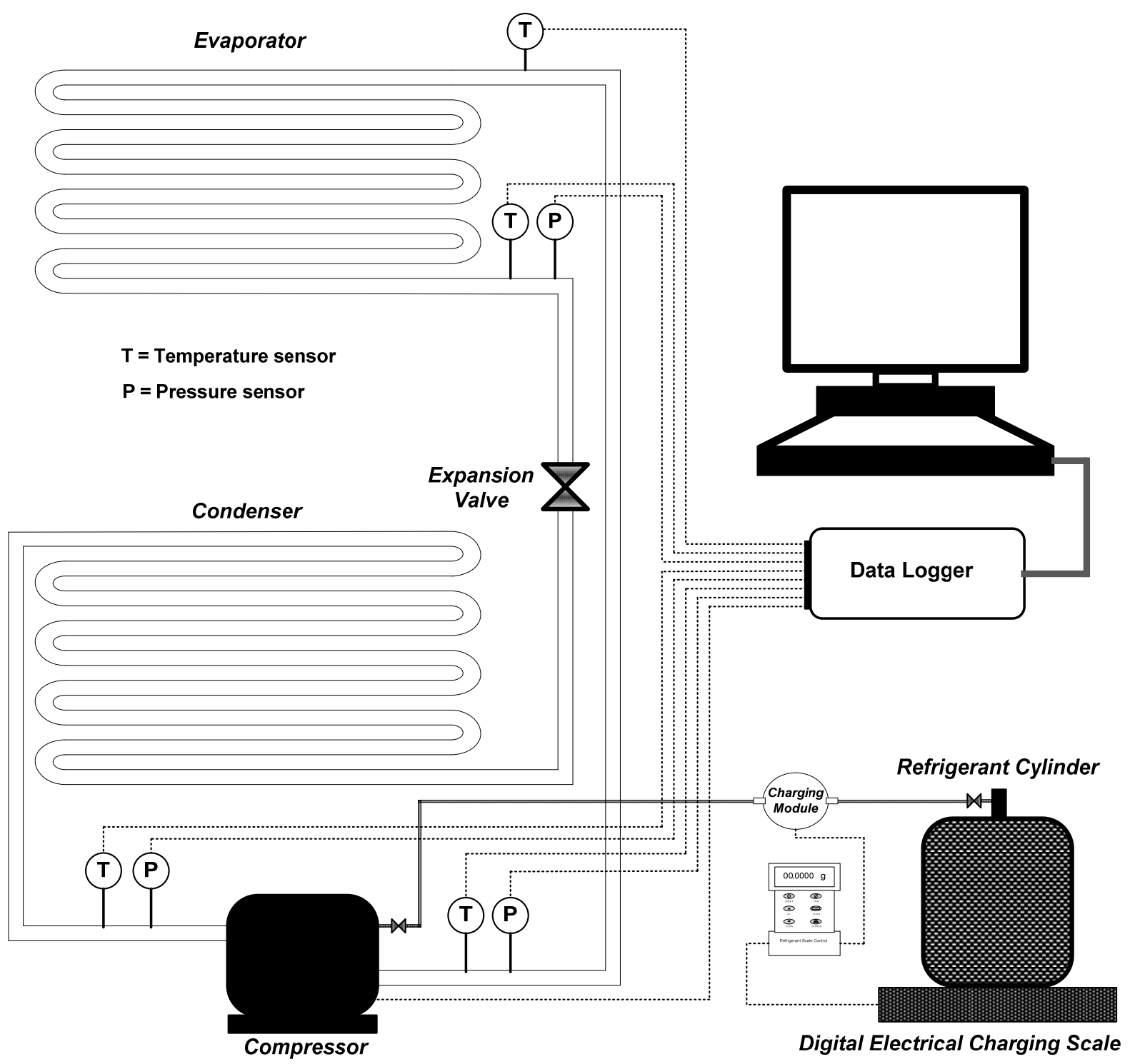

Figure 2. Schematic diagram of the experiment set-up and charging system.

The refrigerator's performance has been investigated with no load and closed door condition. The refrigerator was fitted with the thermocouples, pressure transducers, and power meter, and the other components remained intact.

\subsection{Experiment Condition}

In order to carry out the tests, the sequence of the clauses in international standard of household refrigerating standard, refrigerator-freezers characteristics and test methods were considered. The refrigerator was placed in a temperature controlled room and all experiments have been done in a steady-state operating condition. There was no ceiling fan and air conditioning system to force the movement of air inside the room. Therefore, heat transfer occurred by natural convection in the condenser and refrigerator walls [30].

\subsection{Experiment Procedure}

The same procedure was used for all experiments. Nanofluids were prepared based on the proposed method in the literature. Refrigerant and nanoparticle in this experiment were $\mathrm{R} 134 \mathrm{a}$ and $\mathrm{Al}_{2} \mathrm{O}_{3}$. As the baseline experiment, the system was operated with $\mathrm{R} 134 \mathrm{a}$ and polyolester oil (POE) as a lubricant. In this study, nano-refrigerant was a mixture of $\mathrm{Al}_{2} \mathrm{O}_{3}$ nanoparticles, POE lubricant oil, and R134a refrigerant. First, the required amount 
of $\mathrm{Al}_{2} \mathrm{O}_{3}$ nanoparticles and POE lubricant oil were mixed and sonicated for at least $30 \mathrm{~min}$ to achieve a homogenized mixture before being injected to the compressor. Finally, R134a was charged into the system. The thermocouples, pressure transducers, and power meter were installed on the system (Figure 2) and connected to the data logger to record the required data during all experiments. Vacuum and pressurize tests were performed before and after charging the refrigerant for at least $30 \mathrm{~min}$ to ensure that there was no leakage in the system.

To ensure that the previous working fluid was cleaned out of the passages, the fluid was driven out and the system was washed with based refrigerant and lubricant. It was done by charging the base lubricant into the compressor, then evacuating the system from air and moisture, followed by charging the system with refrigerant, and finally making it run for a few hours with the base fluid passing within the system. At the end, the system was made empty from refrigerant, and the oil was driven out from the compressor.

\subsection{Refrigeration System Performance}

Generally, heat travels from a hot space to a cold space due to a certain temperature difference. However, in refrigeration systems, it is done in the opposite direction as heat transfers from a lower temperature region to a higher temperature one. Figure 3, shows a schematic of a vapor compression refrigeration system.
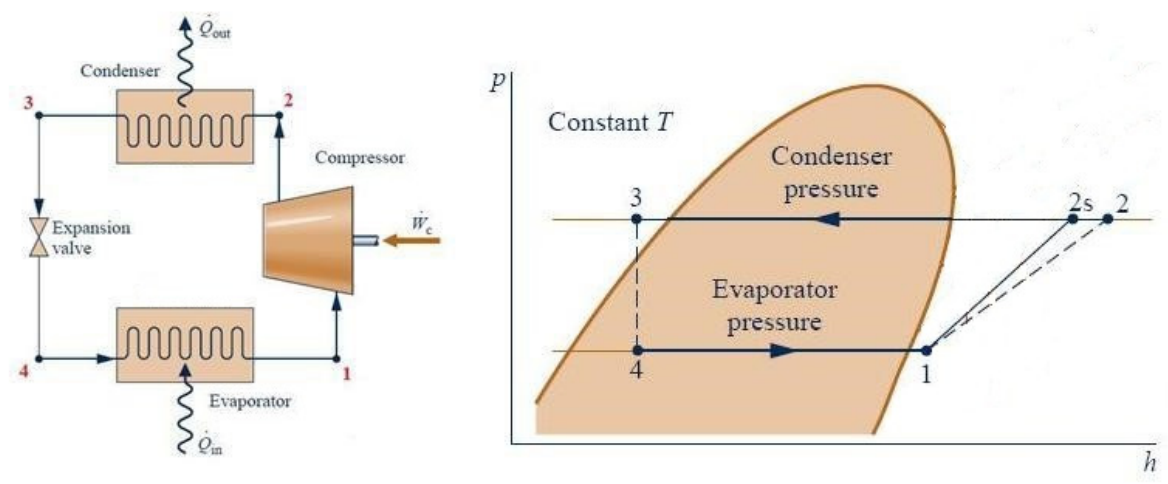

Figure 3. Schematic of a vapor compression system (Adapted from [31]).

The ratio of the cooling or refrigeration capacity (desired output) to the energy input into the system (required input) is called the coefficient of performance (COP), and expressed as:

$$
\text { COP }=\frac{\text { Cooling.capacity }}{\text { Work.input }}=\frac{Q_{r f}}{W_{\text {net, }, \text { in }}}
$$

According to Figure 3, the refrigeration cycle is divided into four stages during which the properties of refrigerant change. Based on thermodynamics, heat transfer characteristics and thermal performance in each stage are explained on the following.

The compressor is the main power-consuming device in the refrigeration system. This energy is used to increase the pressure of the refrigerant vapor and to circulate it through the system. Consequently, the temperature of vapor refrigerant rises which in turn increases the enthalpy of the refrigerant at the outlet of the compressor.

The compressor work is determined with according to the $P$ - $h$ diagram and can be written as:

$$
w=\left(h_{2}-h_{1}\right)
$$

where $h_{2}$ and $h_{1}$ are the enthalpies of refrigerant at the outlet and inlet of the compressor, respectively.

The compressor of the set-up refrigerator is a hermetic reciprocating type, (220 Volts, $50 \mathrm{~Hz}$ ) that is thermally protected, and design for use with R-134a. 
A condenser operates as a heat transfer device to release the heat from high-pressure superheated refrigerant vapor (discharged from the compressor) to the surrounding. As a result of heat rejection in the condenser, vapor refrigerant becomes a liquid at the outlet. Heat transfer rate in the condenser is calculated by:

$$
q_{\text {con }}=\left(h_{3}-h_{2}\right)
$$

In this study, condenser is the natural convection cooling type.

Capillary tube operates as an expansion valve. The pressure of the liquid refrigerant is reduced by the capillary tube. The pressure of the liquid drops slightly in the first two-thirds of the length of the capillary tube. In current refrigerator, the capillary tube has $0.75 \mathrm{~mm}$ inside diameter and $3400 \mathrm{~mm}$ length.

The evaporator absorbs heat from its surroundings (inside refrigerator and freezer space) and transfers it to the refrigerant inside the evaporator. The refrigerant phase changes during the evaporation process from a liquid to a vapor, and at the evaporator exit is slightly superheated. This slight overdesign ensures that the refrigerant is completely vaporized when entering the compressor. The refrigeration effect is defined as the heat rejected by a unit mass of refrigerant during the evaporating process in the evaporator. It can be written as:

$$
q_{r f}=h_{1}-h_{4}
$$

where $h_{1}$ and $h_{4}$ are the refrigerant enthalpies at the outlet and inlet of the evaporator, respectively.

Refrigerating capacity, or cooling capacity, $Q_{r f}$, is the actual rate of heat which is removed by refrigerant in the evaporator, and can be calculated by [1]:

$$
Q_{r f}=\dot{m}_{r}\left(h_{1}-h_{4}\right)
$$

\subsection{Nano-Refrigerant Properties}

According to the literatures, the physical and thermophysical properties of nanofluid can be calculated based on the following equations $[32,33]$. The specific heat of nanofluids and volume fraction of nanoparticle in the basefluid are expressed as:

$$
\begin{gathered}
C_{p, n f}=\frac{\phi\left(\rho c_{p}\right)_{n}+(1-\phi)\left(\rho c_{p}\right)_{f}}{\phi \rho_{n}+(1-\phi) \rho_{f}} \\
\phi=\frac{V_{n}}{V_{n}+V_{f}}
\end{gathered}
$$

The density of nano-refrigerant, as a physical property of mixture, is introduced by:

$$
\rho_{e f f}=(1-\phi) \rho_{f}+\phi \rho_{n}
$$

where subscripts $f$ and $n$ refer to fluid and nanoparticle, respectively. Dynamic viscosity of nanofluid is determined using the following equation:

$$
\mu_{n f}=\frac{\mu_{f}}{(1-\phi)^{2.5}}
$$

The viscosity of the mixture is related to the viscosity of refrigerant and the volume fraction of nanoparticles.

Enthalpy is a critical parameter in evaporation process for calculating the thermodynamic characteristics of the system and it depends on temperature, pressure, and state of the fluid (Liquid-Vapor). By assuming that the nanoparticles are volatile as basefluid, and that using the low nanoparticle concentration can lead to that the enthalpy difference 
of fluid in the case of using nanoparticle could be relevant to the temperature difference compared to the fluid without nanoparticle. Enthalpies of various fluids are available in different temperatures and pressures. As these data are empirical-based, there is no available data for nano-refrigerants that causes a major gap in the calculations related to application of nano-refrigerants. Therefore, future investigations including experimental and numerical methods are needed to obtain accurate thermophysical properties of nanofluids during evaporation and condensation.

\subsection{Energy Consumption and Energy Efficiency of Refrigerator}

The purpose of the energy consumption test is to check the energy consumption of refrigerator under specific test conditions according to the international standard of household refrigerating standard, refrigerator-freezers characteristics and test methods.

The energy consumption was measured for a period of $24 \mathrm{~h}$ after stable operating conditions. Each test was repeated several times to ensure the reliability of the results.

The measurement of energy consumption was carried out under empty condition with all compartments simultaneously being in operation and has been expressed in kilowatt hours per $24 \mathrm{~h}(\mathrm{kWh} / 24 \mathrm{~h})[30]$.

\section{Results and Discussions}

All experiments were done in the same condition to avoid the effects of external parameters on the results. Figure 4, shows the ambient temperature was controlled during the experiments and it followed the same pattern in all experiments. Relative humidity also was controlled in the accepted range of the international standard.

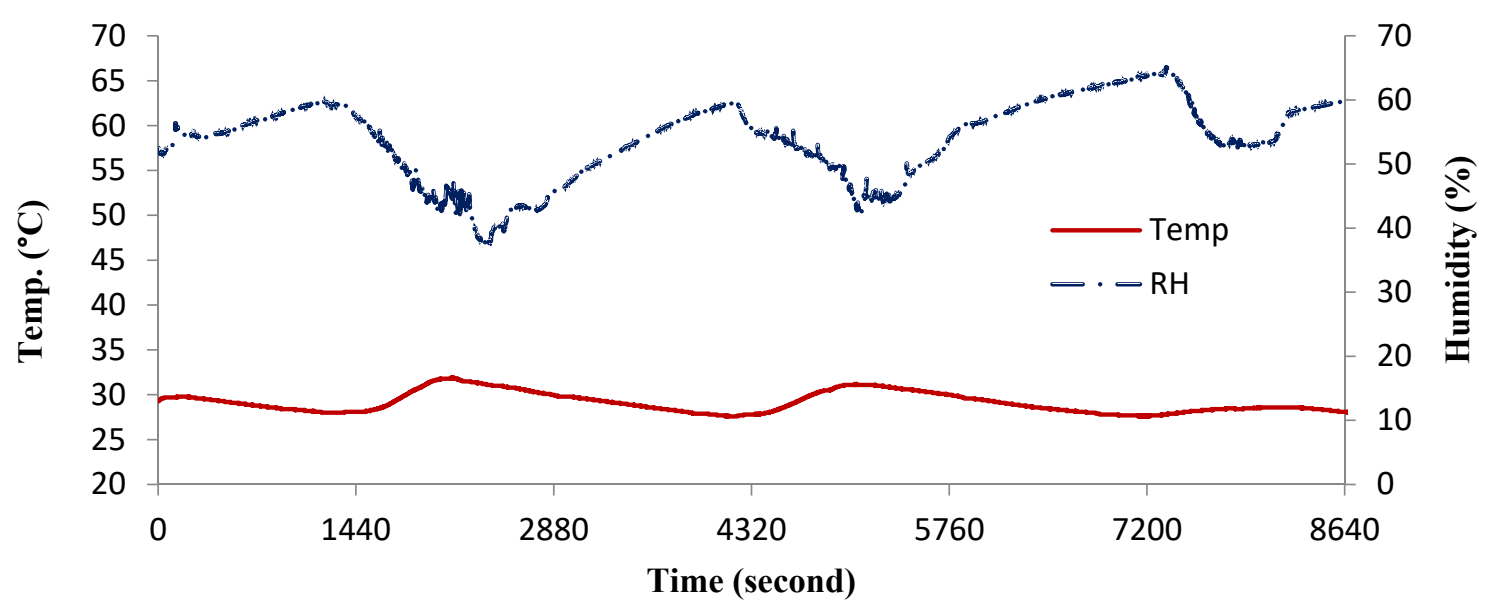

Figure 4. Ambient temperature and relative humidity of test room during experiments.

\subsection{Stability of Nanofluid}

Stability of the prepared nanofluids was investigated while keeping the samples at similar conditions. Experiments show that the stability of nanofluid decreases with by increasing the concentration of nanoparticles. It may happen as a result of increasing agglomeration process. When the number of nanoparticle molecules increases in the constant volume, the interaction of molecules within the solution causes the formation of aggregates due to strong van der Walls forces [34].

Stability of $\mathrm{Al}_{2} \mathrm{O}_{3}$ and polyolester lubricant oil mixtures with $0.05 \%, 0.1 \%$, and $0.3 \%$ mass fractions is shown in Figure 5. All mixtures were stable in the first hour after preparation. Nanofluid with $0.3 \%-\mathrm{Al}_{2} \mathrm{O}_{3}$ started to sediment after some hours. This signifies the insufficient stability of the mixture to be used in the system. Sedimentation of mixture with $0.1 \%-\mathrm{Al}_{2} \mathrm{O}_{3}$ increased at the end of day 1 and it almost completely sedimented on day 3. $0.05 \%-\mathrm{Al}_{2} \mathrm{O}_{3}$ was stable even after 4 days, which proved the possibility for long- 
term stability for the lowest loading concentration of nanoparticles. Therefore, mixtures of $0.05 \%$ and $0.1 \%-\mathrm{Al}_{2} \mathrm{O}_{3}$ nanoparticle and lubricant oil were chosen for this experiment.

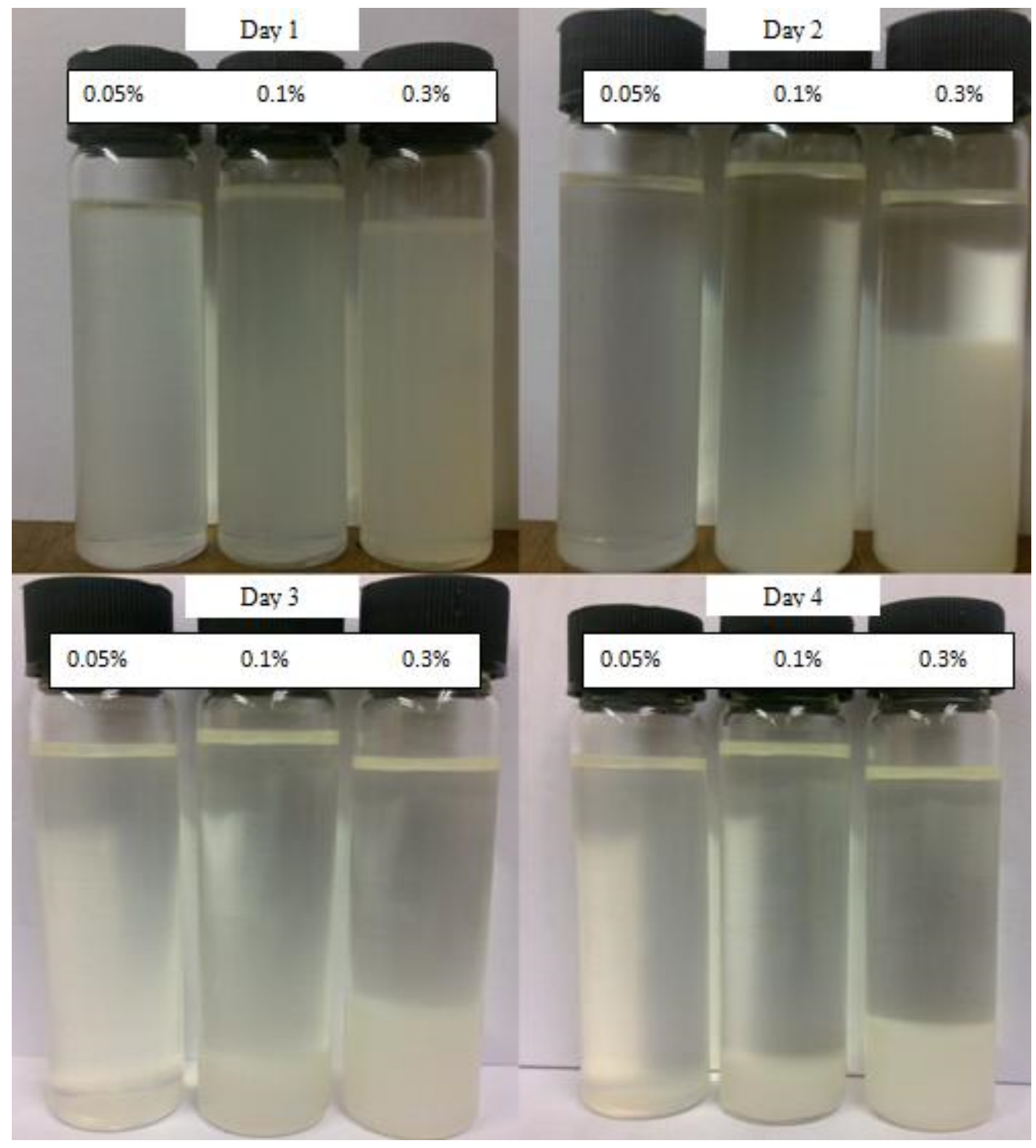

Figure 5. Stability of $\mathrm{Al}_{2} \mathrm{O}_{3}-\mathrm{POE}$ lubricant oil with different concentrations.

\subsection{Effect of Nano-Refrigerant on Evaporator Temperature Gradient}

Evaporator temperature is one of the most important parameters when investigating the heat transfer analysis in refrigeration systems. In the evaporation process, heat is transferred from the cold region into the refrigerant medium through three steps. Heat transfer to the liquid refrigerant before evaporation, during evaporation, and to the refrigerant vapor after completing the evaporation right before leaving the evaporator. These three steps, altogether, are known as refrigeration effect in the evaporator and can be calculated based on Equation (4). According to Equations (4) and (5), the heat transfer and cooling effect in the refrigeration system is explained based on the enthalpy difference of refrigerant fluid between outlet and inlet of the evaporator. Based on the explanation in the nano-refrigerant properties section regarding the enthalpy difference in refrigeration systems in the case of using nanoparticles compared to without nanoparticles, the evaporator performance can be analyzed based on temperature gradient of the evaporator. Higher temperature gradient causes an increase in the cooling effect and performance of the evaporator due to higher enthalpy difference between outlet and inlet. 
Figure 6, shows the temperature gradient of refrigerant during one on-off cycle in the evaporator. As it can be seen, the temperature gradient of nanoparticle based refrigerant is higher than that of the pure refrigerant (R134a). It proves that the heat transfer is improved in the case of using nano-refrigerants. The average temperature gradient improvement in the evaporator was $1.9{ }^{\circ} \mathrm{C}$ (equal to $20.2 \%$ ) when using $0.1 \%-\mathrm{Al}_{2} \mathrm{O}_{3}$. The possible explanation for the increased heat transfer is the enhanced thermophysical properties of nano-refrigerants, such as thermal conductivity due to the existence of solid nanoparticles in the refrigerant. The experiments were conducted for 7 consecutive days in order to evaluate the stability of nano-refrigerant. The obtained results for last day are approximately similar to the acquired results in the initiation of the measurements which proves the stability of nano-refrigerant during the course of experiment. Although higher temperature gradient and consequently higher cooling effect can be achieved at higher nanoparticle concentrations, there is a limitation due to stability problem.

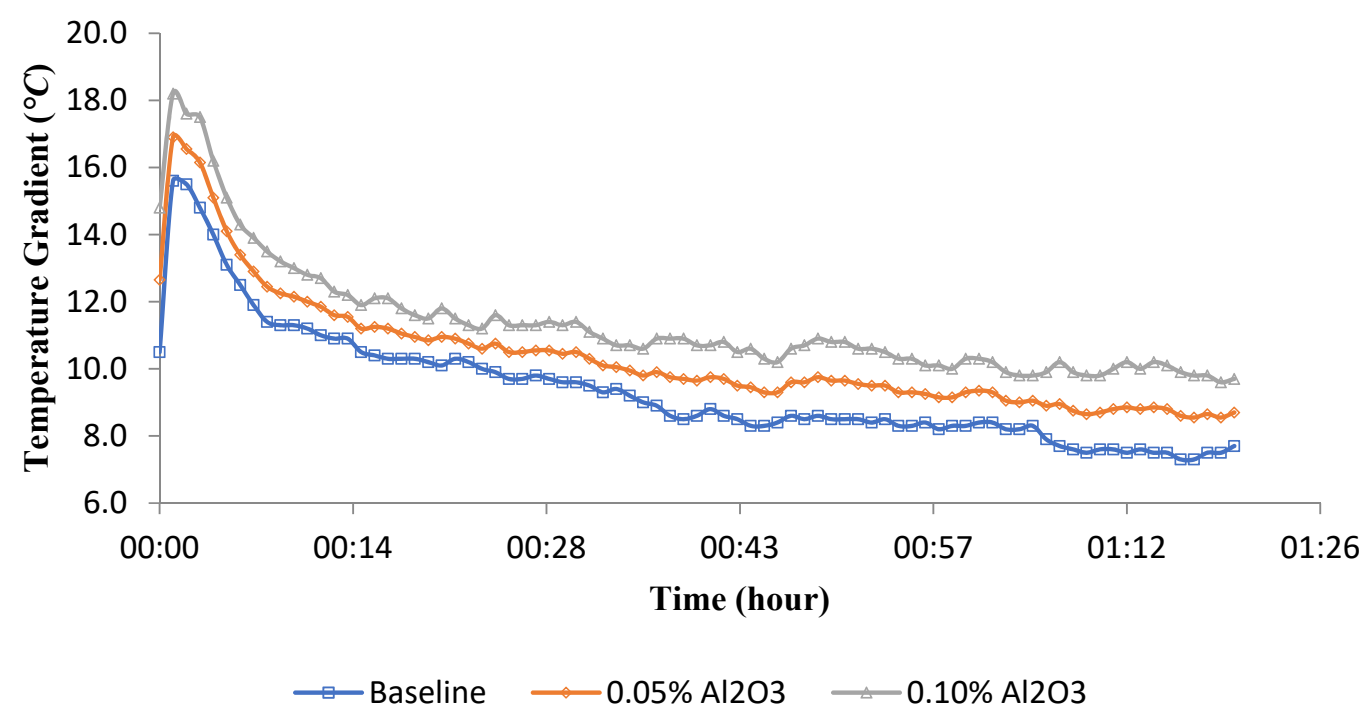

Figure 6. Temperature gradient in evaporator.

\subsection{Energy Consumption by the Compressor}

The energy consumption of each test is shown in Figures 7 and 8. Graphs show decrements in energy consumption after adding nanoparticles to the refrigerant. Every test was done at least three times under the same condition to ensure the repeatability of the results. The energy consumption of the refrigerator with normal refrigerant medium (R134a-POE) was $3.821 \mathrm{kWh} /$ day. The maximum reduction in the energy consumption was around $2.69 \%$ in the case of using $0.1 \%-\mathrm{Al}_{2} \mathrm{O}_{3}$ nanoparticles. The other nanoparticle concentration $\left(0.05 \%-\mathrm{Al}_{2} \mathrm{O}_{3}\right)$ also led to reduction in the energy consumption by $1 \%$. The results from previous experiments on the use of nanoparticle for refrigeration applications showed a similar behavior in terms of energy consumption reduction $[25,26]$. This can lead to significant long-term energy saving and emission reduction, as current refrigeration methods are a main part of environmental pollutants, when considered as a national policy [35].

Analysis of Figures 7 and 8, appeals that despite the equal off-cycles duration the on-cycles duration was decreased after using nano-refrigerant. This means that the cooling velocity of nano-refrigerant system was more quickly that the R134a system. Therefore, energy consumption of the refrigerator was reduced due to the decrease in the total oncycles duration in a complete standard cycle.

The reason behind the decrement in the on-cycles time of the compressor can be the enhancement in the heat transfer characteristics of the evaporator as a result of improved thermophysical characteristics of the refrigerant after dispersing the nanoparticles in the refrigerant. 


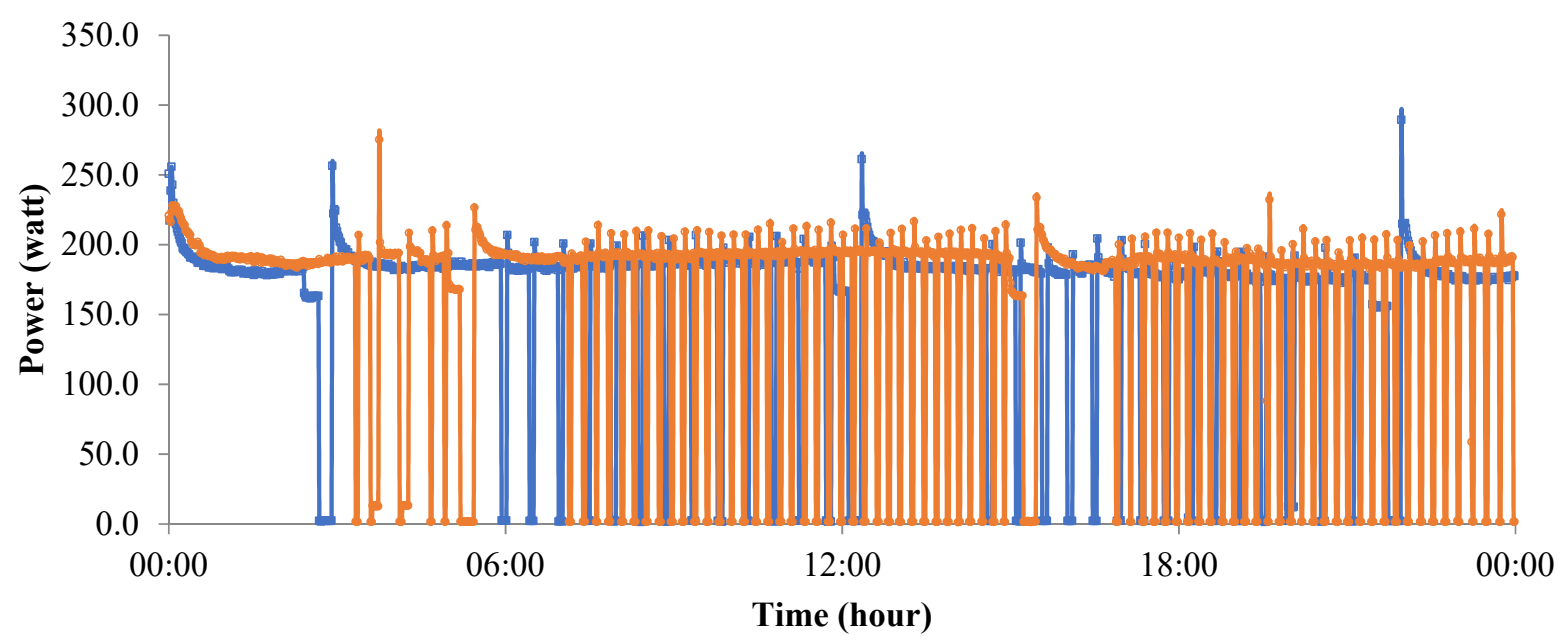

$\longrightarrow$ Baseline $\longrightarrow 0.05 \% \mathrm{Al} 2 \mathrm{O} 3$

Figure 7. Energy consumption of refrigerator with $0.05 \%-\mathrm{Al}_{2} \mathrm{O}_{3}$ and without nanoparticle.

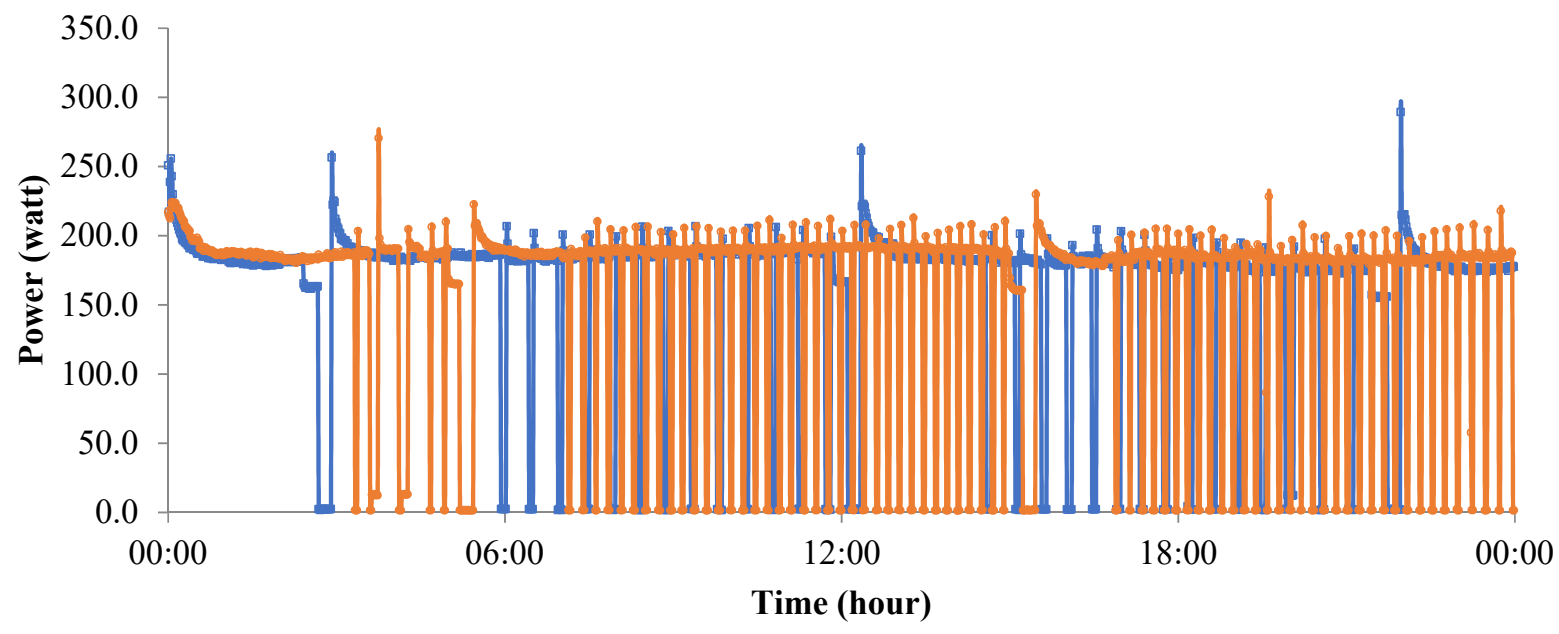

$\longrightarrow$ Baseline $\longrightarrow 0.1 \% \mathrm{Al} 2 \mathrm{O} 3$

Figure 8. Energy consumption of refrigerator with $0.1 \%-\mathrm{Al}_{2} \mathrm{O}_{3}$ and without nanoparticle.

\subsection{Compressor Discharge and Suction Pressure Analysis}

Figures 9 and 10, compare the compressor discharge and suction pressures of the test-rig over one on-off cycle, respectively. These figures show that both pressures were reduced for the case of nano-refrigerants. 


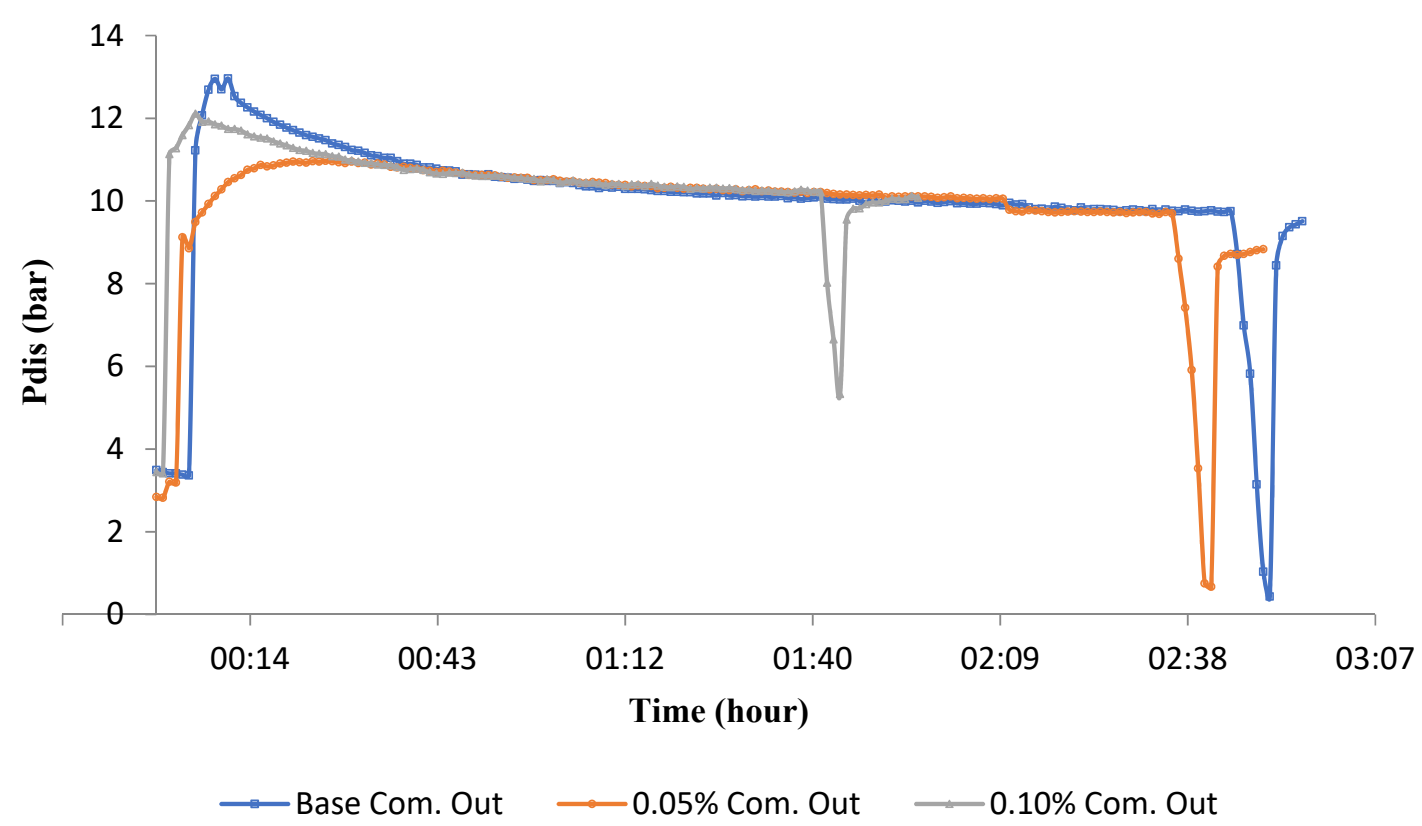

Figure 9. Compressor discharge pressure.

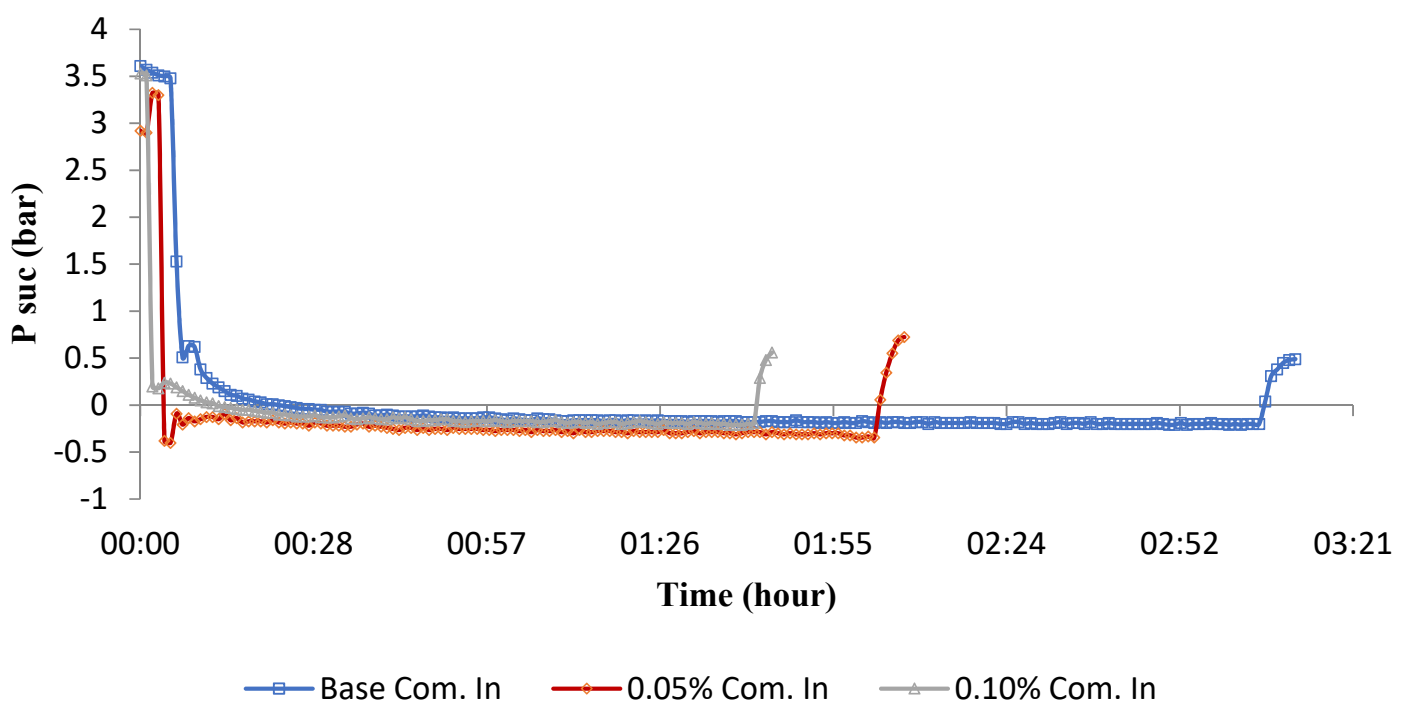

Figure 10. Compressor suction pressure.

For $0.05 \%-\mathrm{Al}_{2} \mathrm{O}_{3}$ nanoparticles, the discharge pressure of the compressor was lower than that of the base fluid at the first minutes of compressor operating time, but it was almost the same as the base fluid after the pressure becomes stable. It shows that small amounts of nanoparticles do not have substantial effect on the discharge pressure, but causes the discharge pressure to decrease at the first minutes of the on-cycle time. Nanorefrigerant with $0.1 \%$ nanoparticles also follows the same trend as $0.05 \%$, but at a higher discharge pressure between those for the base fluid and $0.05 \%$ nanofluid. On the other hand, both Figures 9 and 10 demonstrate that the operating time of compressor in cases of using nanofluids are less than base fluid which causes the energy consumption of the compressor to drop during a complete standard cycle. The reason might be that the nanoparticles improve the heat transfer capability of the refrigerant and then causes the working time of the compressor to decrease. Figure 10 also demonstrates that existence of nanoparticles in the refrigeration system caused the suction pressure and working time of the compressor to reduce. Decreasing the suction pressure of the compressor could be the result of two phenomena: the increase in the pressure drop in the system which is the result 
of increase in the viscosity of the working fluid, as well as the decrease in the discharge pressure of the compressor.

\subsection{Pressure Drop in the System}

Pressure drop is one of the important parameters in fluid systems, especially when the existing fluid is replaced by a new fluid. Figure 11 shows the pressure drop between the outlet and inlet of the compressor. This includes the summation of the pressure drop of the condenser, evaporator, capillary tube, and pipes in the system from inlet to the outlet of the compressor.

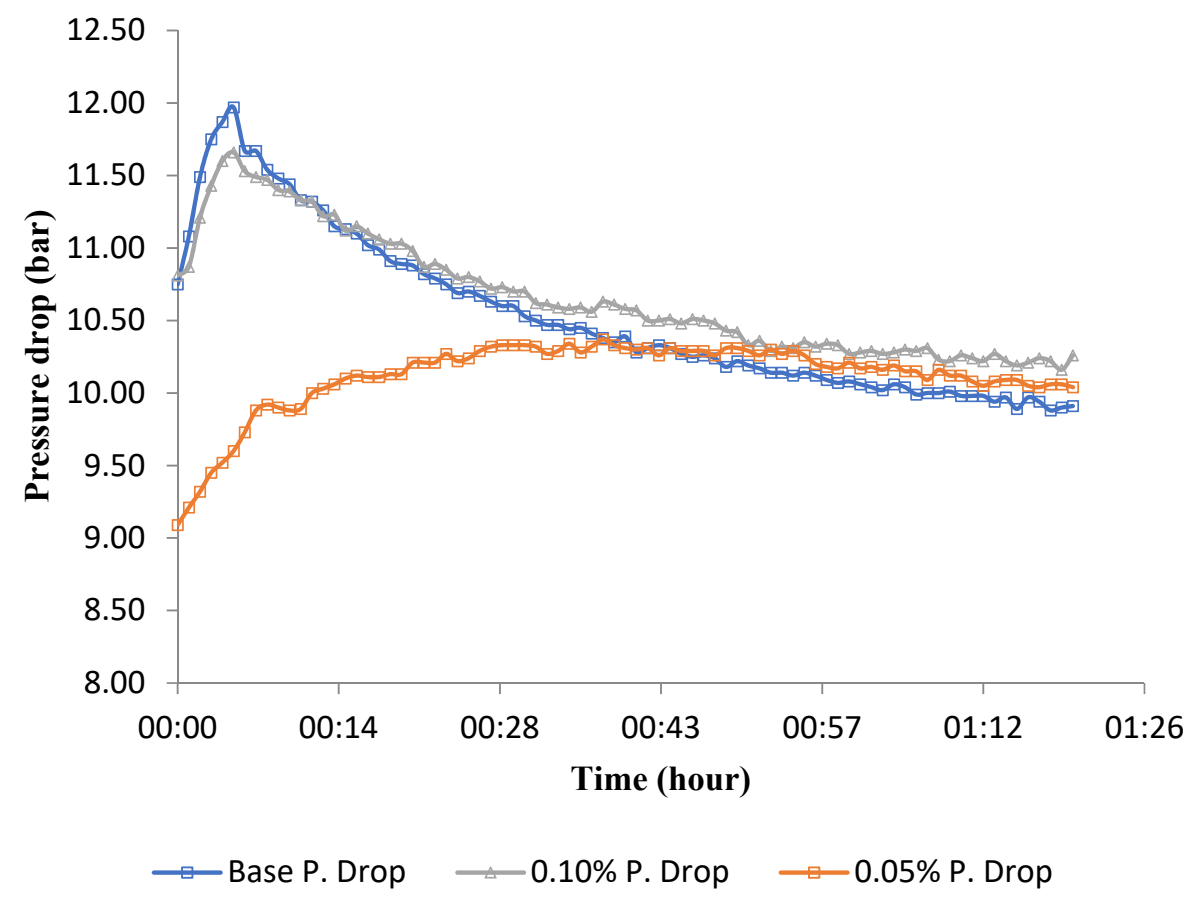

Figure 11. Total pressure drop in the system.

As can be seen, Figure 11 indicates the pressure drop in the system for base fluid and nanofluid with different nanoparticle concentration over one on-off cycle. It shows that base fluid and nano-refrigerant with $0.1 \%$ nanoparticle have almost the same pressure drops. $0.1 \%$ nano-refrigerant owns less pressure drop at the beginning of the cycle. However, its pressure drop increases slightly and reaches to well above that of the baseline at the end of the cycle. Nano-refrigerant with $0.05 \%-\mathrm{Al}_{2} \mathrm{O}_{3}$ follows a different pattern. Apparently, the pressure drop in the beginning of the cycle is much less than those of the other samples. It increases slightly during the initial one-third of the cycle, reaches to the same pressure drop as other experiments, and follows the same pattern during the rest of the cycle. Domination of the lubricity characteristic of nanoparticle in low concentration to the increasing of the density and viscosity due to adding solid particles to the fluid could be the reason. Therefore, increasing the concentration of nanoparticle in the base fluid causes to increase pressure drop and more energy consumption in each on-cycle.

\section{Conclusions}

A test-rig was constructed in order to evaluate the performance of a household refrigerator-freezer using refrigerant R-134a as a working fluid. The test-rig included instrumentation to measure the thermodynamic properties of the system. The energy consumption test was used to evaluate energy consumption of the refrigerator. The system was tested by the normal working fluid, as well as $\mathrm{Al}_{2} \mathrm{O}_{3}$ nano-refrigerant with different nanoparticle concentrations. Finally, all data were compared to evaluate the effect of nanorefrigerant on the thermodynamic performance, heat transfer characteristics, and energy 
efficiency of the domestic refrigerator. After the successful investigation of the measured parameters, the following conclusions have been drawn:

- Stability of $\mathrm{Al}_{2} \mathrm{O}_{3}$ nano-lubricant oil decreases by increasing the nanoparticle concentration in the base fluid. Therefore, application of nanofluid with high nanoparticle concentration is limited and alternative preparation methods and using additives are needed to improve the stability. However, nanofluid with low nanoparticle concentration is stable for longtime;

- Evaporator temperature gradient is increased by using nano-refrigerant. It proves that thermodynamic behavior of fluid is improved. An increment of $20.2 \%$ occurred at the temperature gradient of the evaporator for $0.1 \%-\mathrm{Al}_{2} \mathrm{O}_{3}$;

- It has been found that the electricity consumption of the refrigerator was $2.69 \%$ lower than that of the base fluid (R134a) when $0.1 \%-\mathrm{Al}_{2} \mathrm{O}_{3}$ nanoparticle was added to the system. This value was $1 \%$ for the case of $0.05 \%-\mathrm{Al}_{2} \mathrm{O}_{3}$;

- It is apparent from the data that the on-cycles duration was less for nano-refrigerants, but off-cycles duration was nearly the same for both baseline and nanofluid. It proves that the cooling velocity in nano-refrigerant system was happened quicker than the normal refrigerant. This can be a reason of reduction in energy consumption during a complete standard cycle;

- Suction and discharge pressures of the compressor decreased when using nanorefrigerant compared to the case of pure refrigerant. The result of increasing the pressure drop in the system due to adding nanoparticles to the fluid appears in the suction pressure and its effects on the discharge pressure;

- Effect of nano-refrigerant on the performance of the compressor could be a reason for decreasing the discharge pressure of the compressor;

- Finally, it can be concluded that using nanoparticles in a refrigeration system can improve thermodynamic characteristics and decrease energy consumption of a domestic refrigerator.

\section{Recommendations}

The present research investigated the performance of the domestic refrigerator using nano-refrigerant. In fact, the feasibility of using nano-refrigerant as a refrigerant medium in domestic refrigerator was taken into account. Utilization of nano-refrigerant requires a wide range of information about the properties of the nanofluid such as enthalpy, viscosity, thermal conductivity, and compatibility of the nano-refrigerant with the other material in the system. Compatibility is very important and should be examined for all parts of the system to ensure that there are no negative effects on the system components in the short and long run.

The following recommendations can be suggested for the future research on the application of nano-refrigerant: overcoming the stability problem, direct preparation method for nano-refrigerant, measuring the fundamental properties of nano-refrigerant especially in cases where the boiling temperature of refrigerant is lower than the ambient temperature, the effects of using solid nanoparticles in the refrigeration system, such as compatibility with the equipment, chemical reaction during longtime operation, solubility of the mixture of lubricant oil, refrigerant, and nanoparticle.

Author Contributions: F.S.J.: Conceptualization, Methodology, Investigation, Writing-Original Draft, Writing-Review \& Editing. R.S.: Supervision, Validation, Project administration, Funding acquisition. All authors have read and agreed to the published version of the manuscript.

Funding: This research is supported by High Impact Research MoE Grant UM.C/625/1/HIR/MoE/ ENG/40 from the Ministry of Education Malaysia.

Institutional Review Board Statement: Not applicable.

Informed Consent Statement: Not applicable. 
Data Availability Statement: The data presented in this study are available on request from the corresponding author.

Conflicts of Interest: The authors declare no conflict of interest.

\section{References}

1. Wang, S.K. Handbook of Air Conditioning and Refrigeration, 2nd ed.; McGraw Hill: New York, NY, USA, 2000.

2. Althouse, A.D.; Turnquist, C.H.; Bracciano, A.F.; Bracciano, D.C.; Bracciano, G.M. Modern Refrigeration and Air Conditioning, 9 th ed.; Goodheart-Willcox: Tinley Park, IL, USA, 2004.

3. Aslfattahi, N.; Saidur, R.; Arifutzzaman, A.; Sadri, R.; Bimbo, N.; Mohd Sabri, M.F.; Maughan, P.A.; Bouscarrat, L.; Daw-son, R.J.; Mohd Said, S.; et al. Experimental investigation of energy storage properties and thermal conductivity of a novel organic phase change material/MXene as A new class of nanocomposites. J. Energy Storage 2020, 27, 101115. [CrossRef]

4. Abdelrazik, A.; Tan, K.H.; Aslfattahi, N.; Arifutzzaman, A.; Saidur, R.; Al-Sulaiman, F.A. Optical, stability and energy performance of water-based MXene nanofluids in hybrid PV/thermal solar systems. Solar Energy 2020, 204, 32-47. [CrossRef]

5. Aslfattahi, N.; Samylingam, L.; Abdelrazik, A.S.; Arifutzzaman, A.; Saidur, R. MXene based new class of silicone oil nanofluids for the performance improvement of concentrated photovoltaic thermal collector. Sol. Energy Mater. Sol. Cells 2020, $211,110526$. [CrossRef]

6. Aslfattahi, N.; Saidur, R.; Sabri, M.F.M.; Arifutzzaman, A. Experimental investigation on thermal stability and enthalpy of eutectic alkali metal solar salt dispersed with $\mathrm{MgO}$ nanoparticles. In Proceedings of the 4th International Tropical Renewable Energy Conference, Bali, Indonesia, 14-16 August 2019.

7. Das, L.; Habib, K.; Saidur, R.; Aslfattahi, N.; Yahya, S.M.; Rubbi, F. Improved thermophysical properties and energy efficiency of aqueous ionic liquid/MXene nanofluid in a hybrid PV/T solar system. Nanomaterials 2020, 10, 1372. [CrossRef] [PubMed]

8. Das, S.; Choi, S.U.; Yu, W.; Pradeep, T. Nanofluids Science and Technology, 1st ed.; Wiley: New Jersey, NJ, USA, 2008.

9. Rubbi, F.; Habib, K.; Saidur, R.; Aslfattahi, N.; Yahya, S.M.; Das, L. Performance optimization of a hybrid PV/T solar system using Soybean oil/MXene nanofluids as A new class of heat transfer fluids. Solar Energy 2020, 208, 124-138. [CrossRef]

10. Aslfattahi, N.; Saidur, R.; Sidik, N.A.C.; Sabri, M.F.M.; Zahir, M.H. Experimental assessment of a novel eutectic binary molten salt-based hexagonal boron nitride nanocomposite as a promising PCM with enhanced specific heat capacity. J. Adv. Res. Fluid Mech. Therm. Sci. 2020, 68, 73-85. [CrossRef]

11. Samylingam, L.; Aslfattahi, N.; Saidur, R.; Yahya, S.M.; Afzal, A.; Arifutzzaman, A.; Tan, K.H.; Kadirgama, K. Thermal and energy performance improvement of hybrid PV/T system by using olein palm oil with MXene as a new class of heat transfer fluid. Sol. Energy Mater. Sol. Cells 2020, 218, 110754. [CrossRef]

12. Aslfattahi, N.; Saidur, R.; Arifutzzaman, A.; Abdelrazik, A.S.; Samylingam, L.; Sabri, M.F.M.; Sidik, N.A.C. Improved thermophysical properties and energy efficiency of hybrid PCM/graphene-silver nanocomposite in a hybrid CPV/thermal solar system. J. Therm. Anal. Calorim. 2020, 142, 1-18.

13. Aslfattahi, N.; Saidur, R.; Sabri, M.F.M.; Arifutzzaman, A. Thermal conductivity and rheological investigation of aqueous poly (ethylene) glycol/MXene as a novel heat transfer fluid. In AIP Conference Proceedings; AIP Publishing LLC.: New York, NY, USA, 2021.

14. Parashar, N.; Aslfattahi, N.; Yahya, S.M.; Saidur, R. ANN Modeling of Thermal Conductivity and Viscosity of MXene-Based Aqueous IoNanofluid. Int. J. Thermophys. 2021, 42, 1-24. [CrossRef]

15. Parashar, N.; Aslfattahi, N.; Yahya, S.M.; Saidur, R. Prediction of the Dynamic Viscosity of MXene/Palm Oil Nanofluid Using Support Vector Regression; AIP Publishing LLC.: New York, NY, USA, 2021.

16. Abdullah, N.; Saidur, R.; Zainoodin, A.M.; Aslfattahi, N. Optimization of electrocatalyst performance of platinum-ruthenium induced with MXene by response surface methodology for clean energy application. J. Clean. Prod. 2020, 277, 123395. [CrossRef]

17. Abdelrazik, A.; Tan, K.H.; Aslfattahi, N.; Saidur, R.; Al-Sulaiman, F.A. Optical properties and stability of water-based nanofluids mixed with reduced graphene oxide decorated with silver and energy performance investigation in hybrid photovoltaic/thermal solar systems. Int. J. Energy Res. 2020, 44, 11487-11508. [CrossRef]

18. Krishna, Y.; Saidur, R.; Aslfattahi, N.; Faizal, M.; Ng, K.C. Enhancing the thermal properties of organic phase change material (palmitic acid) by doping MXene nanoflakes. In AIP Conference Proceedings; AIP Publishing LLC.: New York, NY, USA, 2020.

19. Krishna, Y.; Aslfattahi, N.; Saidur, R.; Faizal, M.; Ng, K.C. Fatty acid/metal ion composite as thermal energy storage materials. SN Appl. Sci. 2020, 2, 1-10. [CrossRef]

20. Mahbubul, I.M.; Saidur, R.; Amalina, M.A. Pressure Drop Characteristics of $\mathrm{TiO}_{2}-\mathrm{R} 123$ Nanorefrigerant in a Circular Tube. Eng. e-Trans 2011, 6, 124-130.

21. Mahbubul, I.M.; Saidur, R.; Amalina, M.A. Investigation of Viscosity of R123-TiO 2 Nanorefrigerant. Int. J. Mech. Mater. Eng. 2012, 7, 146-151.

22. Peng, H.; Ding, G.; Jiang, W.; Hu, H.; Gao, Y. Heat transfer characteristics of refrigerant-based nanofluid flow boiling inside a horizontal smooth tube. Int. J. Refrig. 2009, 32, 1259-1270. [CrossRef]

23. Peng, H.; Ding, G.; Hu, H. Effect of surfactant additives on nucleate pool boiling heat transfer of refrigerant-based nanofluid. Exp. Therm. Fluid Sci. 2011, 35, 960-970. [CrossRef]

24. Henderson, K.; Park, Y.G.; Liu, L.; Jacobi, A.M. Flow-boiling heat transfer of R-134a-based nanofluids in a horizontal tube. Int. J. Heat Mass Transf. 2010, 53, 944-951. [CrossRef] 
25. Ding, G.; Peng, H.; Jiang, W.; Gao, Y. The migration characteristics of nanoparticles in the pool boiling process of nanorefrigerant and nanorefrigerant-oil mixture. Int. J. Refrig. 2009, 32, 114-123. [CrossRef]

26. Saidur, R.; Kazi, S.N.; Hossain, M.S.; Rahman, M.M.; Mohammed, H.A. A review on the performance of nanoparticles suspended with refrigerants and lubricating oils in refrigeration systems. Renew. Sustain. Energy Rev. 2011, 15, 310-323. [CrossRef]

27. Bi, S.; Shi, L.; Zhang, L.L. Application of nanoparticles in domestic refrigerators. Appl. Therm. Eng. 2008, 28, 1834-1843. [CrossRef]

28. Bi, S.; Guo, K.; Liu, Z.; Wu, J. Performance of a domestic refrigerator using $\mathrm{TiO}_{2}-\mathrm{R} 600$ a nano-refrigerant as working fluid. Energy Convers. Manag. 2011, 52, 733-737. [CrossRef]

29. Kedzierski, M.A.; Gong, M. Effect of CuO nanolubricant on R134a pool boiling heat transfer. Int. J. Refrig. 2009, 32, 791-799. [CrossRef]

30. Kedzierski, M.A. Effect of $\mathrm{Al}_{2} \mathrm{O}_{3}$ nanolubricant on R134a pool boiling heat transfer. Int. J. Refrig. 2011, 34, 498-508. [CrossRef]

31. Bartelt, K.; Park, Y.; Liu, L.; Jacobi, A. Flow-Boiling of R-134a/POE/CuO Nanofluids in a Horizontal Tube. In Proceedings of the International Refrigeration and Air Conditioning Conference, Champaign and Urbana, West Lafayette, IN, USA, 14-17 July 2008.

32. Standard, BS EN ISO 15502:2005: Household refrigerating appliances. In Characteristics and Test Methods; British Standard/European Standard/International Organization for Standardization, BSI Standards Publication: London, UK, 2005.

33. Micael, J.M.; Shapiro, H.N.; Boettner, D.D.; Bailey, M.B. Fundamentals of Engineering Thermodynamics, 7th ed.; Wiley: Hoboken, NJ, USA, 2011.

34. Pak, B.C.; Cho, Y.I. Hydrodynamic and Heat Transfer Study of Dispersed Fluids with Submicron Metallic Oxide Particles. Exp. Heat Transf. 1998, 11, 151-170. [CrossRef]

35. Brinkman, H.C. The Viscosity of Concentrated Suspensions and Solutions. J. Chem. Phys. 1952, 20, 571. [CrossRef] 